\title{
Supersized votes: ballot length, uncertainty, and choice in direct legislation elections
}

\author{
Peter Selb
}

\begin{abstract}
Voters in polities that make heavy use of direct democracy are frequently confronted with ballots that contain a multitude of propositions. Claims that direct legislation elections overwhelm voters with choices they are not competent to make should particularly apply to such demanding settings. Yet, evidence on the effects of lengthy ballots on voting behavior is scant. This study reviews theories of decision-making under uncertainty, and tests their predictions in a mixed heteroscedastic model of vote choice that is fitted to a unique collection of survey and contextual data on Swiss referendums. Increasing ballot length is demonstrated to interfere with the voters' ability to translate their political preferences into consistent policy choices.
\end{abstract}

Keywords Direct legislation elections · Heteroscedastic probit · Multiple propositions · Status quo bias · Uncertainty · Voting behavior

JEL Classification D72 · D81 · C25

"It's like voting a bed quilt!"

A Portland police officer, after leaving the voting booth at the 1910 Oregon state ballot which listed 32 referendums and initiatives, quoted in Bowler and Donovan (1998, 13).

\section{Introduction}

Direct legislation, i.e., lawmaking by popular votes rather than by elected representatives, puts considerable information demands on voters. Frequently, the propositions at stake are

P. Selb (凶)

Department of Politics and Administration, University of Konstanz, Universitaetsstrasse 10,

78457, Konstanz, Germany

e-mail: peter.selb@uni-konstanz.de 

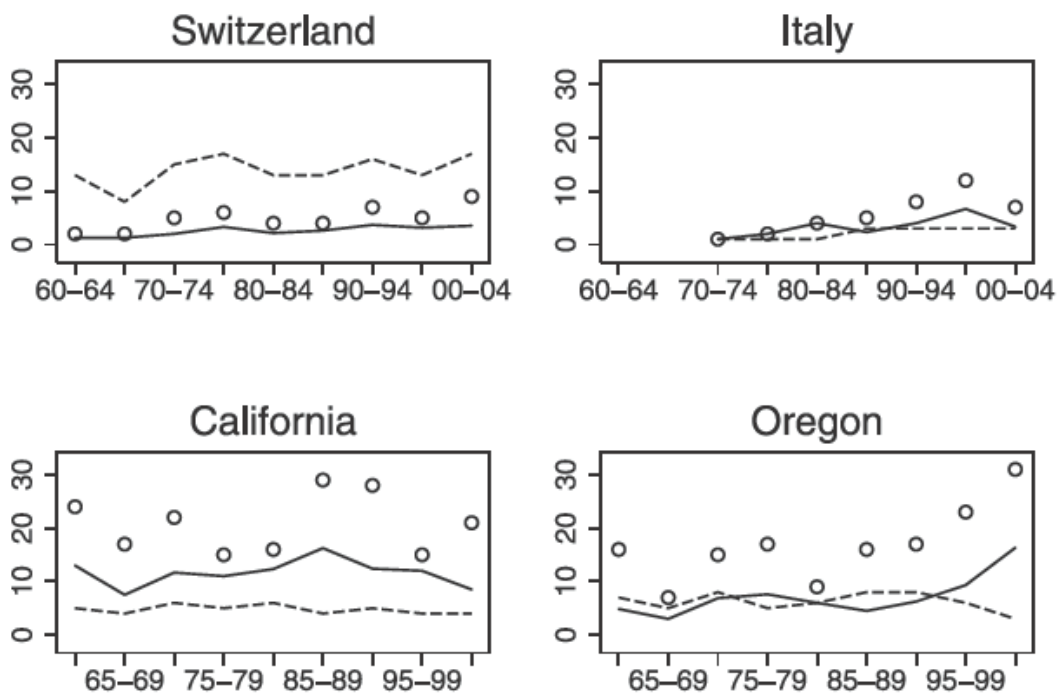

Fig. 1 Numbers of direct legislation elections (dashed lines), average (solid lines) and maximum numbers of propositions (circles) in 'heavy user' countries and states, 5-year periods, 1960-2004. Source: Research and Documentation Centre on Direct Democracy (C2D), Geneva (http://c2d.unige.ch/)

highly complex, the broader public's knowledge of these issues is scant, and decisionmaking guidance that may help to reduce information costs, such as partisan cues and prominent political leaders, is typically less visible in a referendum ${ }^{1}$ than in a parliamentary or a presidential election campaign. This has led many observers to conclude that referendums confront ordinary voters with choices they are not competent enough to make (e.g., Cronin 1989; Magleby 1984). ${ }^{2}$

If voters had a hard time deciding on a single complex proposition, ballots that contain a multitude of substantially diverse bills presumably would complicate matters further. In some countries and states, these complex ballots are the rule rather than the exception. Figure 1 shows some of the more drastic examples. The Swiss, still the "unchallenged champions in national referendums" (Christin et al. 2002, 761), voted on an average of 3.8 national propositions on 125 ballots between 1960 and 2004. On May 18, 2003, the electorate had to decide on a bundle of 9 propositions, covering a vast range of issues, such as the reorganization of the armed forces, a ban on Sunday driving, a moratorium on nuclear energy, rent control, and public health, amongst others. ${ }^{3}$ Italy held 15 referendums covering 56 propositions between 1971 and 2004, which corresponds to an average ballot length of 3.7

\footnotetext{
${ }^{1}$ I follow the common practice and use the term referendum for all instruments of direct citizen legislation, irrespective of whether they are legally binding or consultative, compulsory or optional, and citizen- or stateinitiated. For a typology of direct democratic instruments see, inter alia, LeDuc (2002).

${ }^{2}$ For an overview of the critiques of direct democracy, see Bowler and Donovan (1998) and Lupia and Matsusaka (2004).

${ }^{3}$ Some cantons, i.e., federal states, also held regional referendums the same day, so the citizens of the canton of Argovia, for example, had to simultaneously vote on 4 additional statewide measures. In Switzerland, referendums are also held at the local level of government. Unfortunately, there is no systematic information on simultaneous local referendums available. We therefore cannot be more precise about the number of communities that also may have held referendums on May 18, 2003, confronting voters with yet another range of issues to be decided on.
} 
proposals. On June 11, 1995, the Italian voters were confronted with 12 proposals concerning house arrest for mafiosi, measures to cut municipal competencies, advertizing on TV, reductions in the power of labor unions, and changes in the Italian electoral system.

Of course, referendums are not only held at the national level, but also (and in fact more frequently) within many countries at regional and local levels of government. To name just the heavy weights in subnational direct democracy, voters in Oregon faced an average of 6.6 propositions per ballot between 1960 and 2004. In California, this figure was even higher, with 11.7 measures per ballot. In November 1988, Californians had to cope with 29 propositions, including five complicated car insurance reform initiatives that received considerable scholarly attention (Bowler and Donovan 1994; Lupia 1994). Two years later, there was another supersized ballot scheduled, encompassing 28 proposals. The record in ballot length for the period considered was established in Oregon on March 3, 2000, when the voters were confronted with 31 proposals covering issues of education, criminal justice, gun control, campaign finance, property taxes, fuel taxes, veterans' loans, zoning for sexually oriented business, income taxes, minimum penalties for felonies, home care services, the utilization of tobacco industry funds, and provisions on the referendum and initiative process itself. ${ }^{4}$

Crowded ballots have provoked harsh critiques even among scholars and pundits who are principally supportive of direct democracy (for an early discussion, see Lapalombara and Hagan 1951). They have argued that an increased number of propositions decreases the voters' levels of awareness of the propositions at stake (Kriesi 2005; Nicholson 2003), thus interfering with the pre-referendum deliberative process (Frey 1994). The resulting voter confusion has been claimed to cause lower turnout and higher drop-off rates at a given referendum (Bowler and Donovan 1998; Bowler et al. 1992), to produce a general climate of voter fatigue that can potentially spill over to parliamentary and executive elections (Lijphart 1997), and to stimulate the voters' inclination to reject propositions, irrespective of their personal wants, needs, and beliefs (Bowler and Donovan 1998). Voters themselves have also expressed their dissatisfaction with crowded ballots: being asked what is bad about ballot proposition elections, 'too many propositions' was one of the most prominent replies in the 1989 California Field Poll (Bowler et al. 1992). However, according to Dubois and Feeney $(1998,153)$, there is "very little scientific research concerning how many issues voters can absorb at a given time", and the existing body of literature exclusively uses aggregate election data to study the effects of lengthy ballots on election outcomes. Its potential for providing insights into the behavior at the level of voters is therefore limited.

This study seeks to advance our understanding of how individual voters react to crowded ballots in several respects. In particular, I will investigate two ways in which ballot length may affect voting behavior: first, I will examine the effects of the number of propositions at stake in a referendum on the direction of the vote choice, i.e., on the voters' propensity to cast a 'Yes' (or rather a 'No') vote on a proposition. Second, I will examine the effects of ballot length on the variance of the vote function that links voters' preferences to their choices. Both aspects of choice relate to the theories of decision-making under uncertainty, which are presented in the following section. Subsequently, I will present a newly released data source that pools surveys on 63 Swiss national ballots held between 1982 and 2003, including 195 propositions and 60'000 respondents. This unique dataset provides a rare opportunity to investigate empirically a research question that turns out to be quite demanding in data terms. Thereafter, I will set up a random-effects heteroscedastic probit model of the vote choice that allows for the simultaneous analysis of both directional and variance-altering

\footnotetext{
${ }^{4}$ Many U.S. counties, cities and districts also submit local ballot measures to a popular vote. Again, there is
} little systematic information available at this level of government (but see, for example, Matsusaka 2005.) 
types of effects. Empirical findings will be presented at the level of individual voters, and at the aggregate level of legislative measures. The study will conclude with a summary and discussion of the results.

\section{Information, uncertainty, and voters' reactions to lengthy ballots}

For an initial indication of how ballot length potentially affects voting behavior, I will first discuss the role of information and uncertainty in decision-making. Voters like any decisionmakers, need information to consistently link their wants and needs to choices. In a referendum context, voters would ideally know their own interests and have clear expectations of whether these interests would be better reflected if the ballot measure was enacted or not, so they could confidently support or oppose the proposition at stake. Given how frequently even experts are perplexed by unintended policy consequences, this task seems to ask very much of ordinary voters. Irrespective of the imponderabilities of ex ante impact assessments, decades of survey research have powerfully documented voters' general lack of political knowledge (see, for example, Sniderman et al. 1993). Considering these findings, we would expect ordinary voters to be deeply uncertain of how ballot measures relate to their own preferences and interests, and thus of which vote to cast on a proposition. ${ }^{5}$

Uncertainty has been incorporated into several theoretical and empirical models of voting behavior (e.g., Alvarez 1999; Bartels 1986; Enelow and Hinich 1984; Shepsle 1972). Although they primarily model voters' perceptions of candidate and party positions, their application to direct legislation elections is straightforward (see Gerber and Lupia 1993, 1995). For heuristic purposes, I have graphed in Fig. 2 a hypothetical voter's $i$ own position, and her positional perceptions of a supportive $(\mathrm{Y})$ and a dismissive $(\mathrm{N})$ stance towards a proposition in a unidimensional policy space. In the left panel, $i, \mathrm{Y}$ and $\mathrm{N}$ are represented by points on the policy continuum, i.e., $i$ exactly knows her own preferences and is fully informed about the policy alternatives; no uncertainty is present in her perceptions of Y and $\mathrm{N}$. If $i$ 's utilities of $\mathrm{Y}$ and $\mathrm{N}$ were distance-based in the classical Downsian sense, $i$ would clearly support the proposition at stake, since her own position is closer to $\mathrm{Y}$ than to $\mathrm{N}$. In the second panel, the position of $i$ and her 'mean' perceptions of $\mathrm{Y}$ and $\mathrm{N}$ are still the same, but this time $i$ is unsure of the exact positions of $\mathrm{Y}$ and $\mathrm{N}$. This uncertainty is represented by probability distributions around $i$ 's mean perceptions of $\mathrm{Y}$ and $\mathrm{N}^{6}{ }^{6}$ Thus, the shaded area below the distributional function of the perceptions of $\mathrm{Y}$ represents the perceived probability that the policy carried out if the proposition was enacted would actually be worse (in terms

Fig. 2 The conception and effect of uncertainty in a hypothetical direct legislation election. $i$ stands for an individual voter's position in a one-dimensional policy space, $\mathrm{Y}$ for the perceived location of a 'Yes' and $\mathrm{N}$ of a 'No' vote
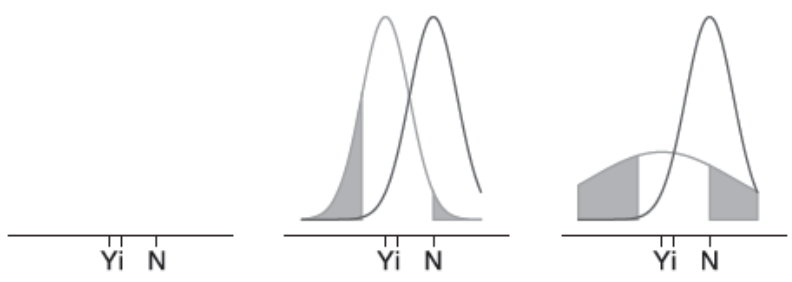

\footnotetext{
${ }^{5}$ It is worth noting that Benz and Stutzer (2004) and Tolbert et al. (2003) found that voters are politically better informed in institutional settings with strong direct democratic elements.

${ }^{6}$ Note that $i$ 's own position is still represented by a point, i.e., it is assumed that the voter is sure of her own stance. However, some recent studies of public opinion have demonstrated that citizens may also be uncertain or ambivalent about their own policy positions (e.g., Alvarez and Brehm 1995, 1997; Alvarez and Franklin 1994).
} 
of $i$ 's expected utility) than the mean perceived policy distribution of N. Since the unshaded area of the distribution of $\mathrm{Y}$ is larger than the shaded area, we would still expect $i$ to support rather than to oppose the bill at stake. However, rising uncertainty would make it more and more difficult for $i$ to decide which alternative to vote for (and for students of voting behavior to predict individual choices and aggregate election outcomes, given the distribution of voters' preferences). In other words, uncertainty is expected to widen the voters' underlying distribution of choices, with their policy preferences being equal. Gerber and Lupia (1993) have demonstrated this effect of uncertainty empirically in their study of 24 Californian referendums and initiatives. They have found that informed voters turned their policy preferences into vote choices significantly more consistently than uninformed voters did.

In the third panel, the distributions of $\mathrm{Y}$ and $\mathrm{N}$ have unequal variances: $i$ is much more unsure of the policy consequences of an enactment of the proposition than she is of an eventual rejection. Here, $i$ 's perceived probability that she will be worse off if the bill passes the referendum, i.e., the shaded area under the distribution of Y, outweighs the probability that she will be better off, i.e., the unshaded area. As a consequence, she is likely to cast a 'No' vote, even though the utility of a 'Yes' vote would be higher for her. Although this last example is hypothetical, illustrating that the voter's uncertainty of the policy consequences of a 'Yes' vote is higher than that of a 'No' vote is not coincidental. In a direct legislation election, the adoption of a proposition typically brings about a change in an existing policy, while a rejection means that the previous legal regulations remain effective and the status quo is preserved. Therefore, voters should be less uncertain of the policy consequences of a 'No' vote, since these usually correspond to their past experiences in that policy domain. A 'Yes' vote, on the other hand, is frequently related to a more or less unknown future, and should therefore be associated with a higher level of uncertainty. In other words, the rejection of a proposition in a direct legislation election may simply result from unequal levels of uncertainty over the alternatives, rather than from the distribution of policy preferences in the electorate. This is one potential explanation for the frequently observed phenomenon labeled status quo bias, i.e., the preference for the current state in decision making (see Kahneman et al. 1991; Quattrone and Tversky 1988; Samuelson and Zeckhauser 1988). Turning to empirical evidence of the status quo bias in direct legislation elections, Bowler and Donovan (1998) have found that the percentages of voters who were still undecided in the run-up to 62 Californian ballot elections were positively related to the later shares of 'No' votes. In the Swiss context, Christin et al. (2002) and Kriesi (2005) have demonstrated that informed voters had a higher average propensity to cast a 'Yes' vote than uninformed voters.

But how does ballot length relate to these effects of information and uncertainty in direct legislation elections? In his aggregate study of voters' awareness of 74 Californian initiatives, Nicholson (2003) found that each additional proposition on a ballot brings about an average decrease of $1 \%$ in the share of voters who reported to be aware of a given ballot measure. Kriesi's (2005) analysis of voting on 144 national propositions in Switzerland has even indicated a $7 \%$ decline in the share of aware voters per additional legislative measure. ${ }^{7}$

\footnotetext{
${ }^{7}$ Kriesi (2005) and Nicholson (2003) have used different measures of awareness and different sets of variables in their linear regression models. However, a nonlinear functional form of the relationship between the number of propositions and voter awareness may also account for these diverging findings: if awareness sharply declined even with moderately increasing ballot lengths, we would already expect a bottoming-out effect at intermediate numbers of propositions. As we have seen from Fig. 1, average and maximum ballot lengths have been considerably higher in California as compared to Switzerland. Therefore, Kriesi (2005)
} 
Assuming that awareness is a precondition or a weak form of information, these findings do not come as a surprise, since information costs will increase with the number of propositions on a ballot, other things being equal. Based on information-theoretic principles, Bowler et al. (1992) even claim that these costs will rise exponentially with increasing ballot length. Voters confronted with crowded ballots, on the other hand, cannot be expected to be naturally inclined to invest more in the acquisition of information than voters in single-proposition referendums. Hence, we would expect voters' uncertainty to rise with increasing numbers of propositions on a ballot. ${ }^{8}$

In line with the previous arguments on voting under uncertainty, it is therefore hypothesized, first, that increasing ballot length will make it more and more difficult for voters to consistently translate their preferences into choices, i.e., the underlying distribution of vote choices will widen with a growing number of propositions at stake, and second, that voters confronted with higher numbers of propositions on a ballot will be more and more inclined to opt for the status quo, i.e., to cast a 'No' vote. ${ }^{\text {' }}$

Direct empirical evidence of these effects of ballot length is nonexistent as pertains to the first hypothesis, a problem that is presumably related to the relatively unfamiliar focus of this assertion on the variance rather than the direction of the voters' choices (see Braumoeller 2006). As to the second directional hypothesis, findings are rare, mixed, and exclusively come from aggregate-level studies. For example, Bowler and Donovan (1998) have found a status quo effect in their analysis of official election results from almost 700 ballot measures in California and Oregon. Accordingly, the share of 'No' votes increased by 0.4 percentage points on average with each additional proposition. In contrast, Mueller (1969) did not find any significant effect of ballot length on the 'No' share in his earlier study of some 1,600 ballots from Los Angeles county over a 50-year period. However, the general problem with aggregate level analyses of the status quo effect is that there is virtually no way to control for the distribution of voter preferences, which therefore has to be assumed to be constant over propositions, or at least uncorrelated with ballot length. In order to adequately test this hypothesis, it is therefore necessary to have data that allows for observing individual preferences and choices over a preferably wide range of propositions and ballots. Of course, this argument applies even to a greater extent to the first hypothesis on choice consistency, since there is virtually no way to test this conjecture with aggregate data alone.

and Nicholson (2003) probably estimated the effect of ballot length on voter awareness over different ranges of the independent variable.

${ }^{8}$ I do not draw a sharp demarcation line between detailed factual information and information cues such as endorsements by trusted political leaders or 'knowing who is behind it' (see Lupia 1992, 1994; Lupia and McCubbins 1998). Although the latter type of information may be less costly than the former, it surely does not come free of charge. Therefore, the argument principally applies to both types of information.

${ }^{9}$ Another feature of lengthy ballots that is frequently claimed to influence voting behavior relates to the positioning of choices on a ballot (for an overview, see Darcy and McAllister 1990; Krosnick and Miller 1998). However, order effects are primarily applicable to decisions where one selects from among a list of options, e.g., candidates competing for offices, and not so much in elections on policy options that have to be approved or rejected one by one (Brockington 2003). Therefore, ballot position effects will not be considered here. 


\section{Data}

This analysis of voting behavior is based on VoxIt - to the best of my knowledge the largest systematic collection of voter survey and contextual data on direct legislation elections. ${ }^{10}$ VoxIt primarily consists of representative voter surveys (the Vox Polls) that have been regularly conducted on the occasion of national referendums and initiatives in Switzerland since 1981. ${ }^{11}$ In each Vox Poll, a regionally stratified sample of approximately 1,000 (700 until 1987) eligible persons have been interviewed on their voting behavior, political attitudes, sociodemographics and related topics, immediately after a respective election day. These data have been standardized, pooled and supplemented with additional data on the campaign context of each proposition (see Kriesi 2005). The first release contains information from almost 60,000 individual respondents at 62 ballot elections including 195 propositions. A large comparative dataset like this is a precondition for studying the effect of ballot length on vote choice, since ballot length varies solely over ballots. I am turning now to the operationalization of the relevant constructs.

Vote choice The measurement of the dependent variable is relatively straightforward. I have used the Vox Poll respondents' reported vote choices on a given proposition with 'Yes' coded 1 and 'No' coded 0 . This implies that non-voters and cases of partial abstention, i.e., voters that voted on some but not all of the propositions on a particular ballot, have been excluded from the analysis. Bowler et al. (1992) and Bowler and Donovan (1998) have demonstrated that lengthy ballots may also cause higher levels of partial abstention or 'voter roll-off'. However, my theoretical concern here is the direction and consistency of the vote choice, and not electoral participation. If roll-off was the voters' primary or even exclusive reaction to rising uncertainty due to increasing ballot length, we could not expect to find any strong effect of ballot length on the voters' choices. ${ }^{12}$

Ballot length Equally straightforward is the operationalization of ballot length. Ballot length is simply the number of propositions on a ballot. This variable ranges from one to a maximum of 9 propositions, which is relatively low as compared to referendums, for example, in California and Oregon (see Fig. 1). The reason for this is not a lower number of propositions, but a higher frequency of election dates in Switzerland: the Swiss Federation holds referendums every 3 to 4 months, while California and Oregon usually call direct democratic elections only once a year (see Fig. 1). However, Kriesi (2005) finding that each additional proposition has decreased the share of voters who were aware of the propositions at stake by 7 percentage points in Switzerland, suggests that voters' uncertainty should rise quickly with relatively few additional propositions, assuming that awareness is something like a prerequisite of informed choices. Thus, a maximum number of 9 proposition (Kriesi analyzed ballots of a maximum length of 7 propositions) should be enough to test our theoretical predictions. For interpretational ease, I have subtracted one proposition from the

\footnotetext{
${ }^{10}$ VoxIt has been built up under the direction of Hanspeter Kriesi (see Kriesi 2005). The data are available from the Swiss Information and Data Archive Services for the Social Sciences SIDOS (http://voxit.sidos. ch). This paper uses version 1.0, released March 2005. VoxIt will be updated regularly to include recent referendums and initiatives. An English documentation is in process. So far, documentation is available in French and German.

${ }^{11}$ Vox polls have been conducted by the Gesellschaft für praktische Sozialforschung GfS on behalf of the Institutes for Political Science of the Universities of Berne, Geneva, and Zurich.

${ }^{12}$ Matsusaka (1995) incorporates limited information in a theory of voter turnout. He argues that the probability of abstention increases with the voter's uncertainty that she is voting for the 'right' alternative.
} 
ballot length score, so that a value of 0 stands for one proposition, a value of 1 stands for two propositions, and so on.

Left-right score The question of how to measure political preferences is far less clear-cut. Since the number of propositions varies over ballots, a measure of preferences needs to be obtained that is both sufficiently specific to capture the peculiarities of a given policy measure and equally valid across propositions on a multitude of substantive issues in order to test our hypotheses. Regarding specificity, a whole set of measures has already been proposed in studies of direct democratic voting behavior. For example, Bowler and Donovan (1998) use indicators for parents with children in private and public schools to determine voters' preferences for school voucher propositions in California and Colorado. In another instance, they successfully employ home ownership to predict approval of a property tax relief measure. Irrespective of how prudent such measures are, they do not lend themselves to comparisons across ballot propositions on a variety of issues, potentially involving multiple interests, values, and expectations. As to the comparability criterion, on the other hand, ideological schemas such as left/right and liberal/conservative seem obvious candidates, since there is, in Zaller's $(1992,26)$ words, "a tendency for people to be fairly consistently 'left' or 'right' or 'centrist' on such disparate value dimensions as economic individualism, opinions toward communists, tolerance of nonconformists, racial issues, sexual freedom, and religious authority". Indeed, many studies have demonstrated that ideological self-placements are linked to voting behavior on a wide variety of propositions in direct legislation elections in the United States and Switzerland (Bowler and Donovan 1998; Branton 2003; Christin et al. 2002; Magleby 1984). Relatedly, Banducci (1998) extracts principal components from actual votes on several propositions on a single ballot, and shows that individuals exhibit meaningful ideological patterns in their choices. I will therefore use voters' left-right self-placements on an 11-point scale ranging from 0 to 10 to determine their policy preferences, which have been included in Vox Polls on 127 propositions.

However, we can hardly expect each and every ballot proposition to fit into that universal ideological scheme. For example, one can well imagine that voters of the religious right and the environmentalist left are equally opposed to permissive provisions on gene technology, although for different reasons. More generally, voters potentially maintain multiple preferences over many political domains, one or several of which may be pertinent to any specific policy question (Alvarez and Brehm 2002). Consequently, I will focus the analysis on propositions that presumably have polarized the electorate along the left-right continuum by using party endorsements as a selection criterion, assuming that parties are pivotal in structuring the public debate on political issues. As opposed to direct legislation elections in California and Oregon, political parties are typically very active in Swiss referendum campaigns. In fact, they frequently initiate optional referendums and popular initiatives, ${ }^{13}$ and their voting recommendations are widely visible in the newspaper coverage and in advertisements. At the same time, there is a broad consensus among voters, political elites and experts as to where to locate these parties in the left-right political space. As Hug and Schulz (2007) demonstrate in their analysis of party manifestos, parliamentary roll-call votes, party endorsements, elite and voter surveys, the four largest parties which cover approximately $90 \%$ of the vote share in national parliamentary elections can be consistently ordered from

\footnotetext{
13 An optional referendum is held if 50,000 voters or eight out of the twenty-six cantons have requested a referendum on, for example, a new or amended federal act, or on an international treaty. A popular initiative is a measure by which a minimum of 100,000 voters may propose a partial or total revision of the Federal Constitution. 100,000 voters correspond to approximately $2 \%$ of the Swiss electorate.
} 
the Social Democrats (SPS) on the left, through the Christian Democrats (CVP) and the Liberals (FDP), to the conservative People's Party (SVP) on the right of the political landscape. Hence, I have selected only those propositions that polarized these parties in this order. Therefore, this analysis will be restricted to propositions on which either the SPS opposed the other three parties, or on which the SPS and the CVP conflicted with the FDP and the SVP, or on which the SPS, the CVP and the FDP opposed the SVP. This criterion applies to 86 propositions on 35 ballots. ${ }^{14}$

Even though this selection makes it highly plausible that voters' left-right orientations may actually play a crucial role in determining their preferences toward the various propositions, the assumption that this applies to the same extent to all of these propositions is very restrictive, since the magnitude of left-right polarization inherent in the selected propositions may still differ. To account for this eventuality, I will let the effect of voters' left-right placements vary over propositions in a random-coefficients framework. Details are given in the modeling section below. Finally, for technical and presentational reasons I have centered the respondents' left-right placements on zero, so that the left-right scale ranges from -5 to 5 , and, by fitting proposition-specific probit models of the vote choice, I have partially reversed the scales so that a low value on the left-right scale will be always associated with a low propensity to cast a 'Yes' vote and vice versa.

Campaign intensity There are many factors apart from ballot length that may affect voters' levels of information, and hence, vote choices. Some of these may also be related to ballot length and thus have to be taken care of in an analysis of the effect of ballot length on vote choice. In particular, the Swiss national government has a certain influence on the composition and content of national ballots, and therefore potentially on the numbers of propositions to be voted on in a given referendum, too. ${ }^{15}$ In some instances, the government explicitly argued that propositions should be considered alone without other issues on the ballot, since these propositions were very important and needed careful consideration on the side of the voters - an argument which, by the way, obviously implies some concerns about the effects of lengthy ballots on voting behavior on the part of the Swiss federal government as well. Among those was, for example, the 1992 referendum on Switzerland's accession to the European Economic Area (EEA), which was at the same time the proposition that triggered the highest campaign intensity of proponents and opponents alike in the long history of direct democracy in Switzerland. If single-proposition ballots generally provoked higher campaign intensities than propositions on longer ballots, we should control for campaign intensity statistically, in order to avoid misattribution of ballot length effects. The reason for this is that intensive campaigns are also claimed to help voters to more consistently translate their preferences into choices, since intensive campaigns tend to raise the level of awareness and information (see, Bowler and Donovan 1998; Gerber and Lupia 1993, 1995; Kriesi 2005; Nicholson 2003). A proposition-specific measure of campaign intensity that is available in VoxIt is the number of advertisements that were placed in Switzerland's largest circulation

\footnotetext{
${ }^{14}$ During selection, I found no indication that party polarization as so defined is systematically related to ballot length. Therefore, the hazards of confounding the effects of ballot length and ideologically inconsistent party endorsements on the translation of the voters' preferences into choices in the subsequent analysis seem limited.

${ }^{15}$ This influence is limited, however. Since 2002, strict deadlines have been imposed for putting referendums and initiatives on the election schedule. This new legal provision, ironically a consequence of a popular initiative itself, has given rise to the nine-proposition ballot of May 2003, since some pending propositions were close to exceeding the time limit.
} 
national newspapers by parties, organizations and referendum committees in the run-up to an election. ${ }^{16}$ These data were taken from a large-scale media content analysis (see, Kriesi 2005). Again, for technical and presentational reasons, this measure has been centered on its mean value so that it expresses deviations in hundreds of advertisements on a proposition from the overall mean. Measures of campaign intensity are available for 85 of the 86 propositions selected so far.

\section{An empirical model of the vote choice}

It has been hypothesized that uncertainty due to crowded ballots affects voters' choices on direct legislation propositions in two distinct ways: first, increasing numbers of propositions are expected to raise voters' propensity to cast a 'No' vote, with their policy preferences being equal. Leaving potential variation of the effect of the policy preference measure over propositions aside for a moment, we may set up this assertion as a simple latent-response model:

$$
y_{i}^{*}=\beta_{0}+\beta_{1} x_{i}+\beta_{2} z_{i}+\epsilon_{i},
$$

where the unobserved response $y_{i}^{*}$ represents the propensity of voter $i$ to cast a 'Yes' vote on a particular proposition, so that the observed choice $y$ will be 1 if $y_{i}^{*}>0$, otherwise 0 , $x$ indicates $i$ 's policy preferences, $z$ is the number of propositions to be voted on at a given referendum, the $\beta$ 's are parameters to estimate, and $\epsilon_{i}$ is an error term. If a standard normal distribution with mean zero and variance $\left(\sigma^{2}\right)$ one is assumed for $\epsilon_{i}$, the model becomes a probit model:

$$
\operatorname{Pr}\left(y_{i}=1 \mid x_{i}, z_{i}\right)=\Phi\left(\beta_{0}+\beta_{1} x_{i}+\beta_{2} z_{i}\right),
$$

where $\Phi(\cdot)$ is the standard normal cumulative distribution function, the probability that $\epsilon_{i}$ is less than the argument. If the status quo bias prediction is correct, we would expect a negative $\beta_{2}$ estimate.

Second, it has been suggested that ballot length widens the voters' underlying distribution of choices, with their preferences being equal. The standard probit model in (2) precludes such heterogeneity by assumption, since $\sigma^{2}$ is fixed at one, and will therefore yield inconsistent estimates in the presence of heteroscedastic errors (Yatchew and Griliches 1985). This problem can be addressed by modeling the heterogeneity directly. ${ }^{17}$ For example, Alvarez and Brehm (1995) have developed a probit variant of Harvey's (1976) multiplicative heteroscedastic regression which assumes the error variance to depend on explanatory variables (ballot length, in our case):

$$
\begin{aligned}
& \operatorname{Pr}\left(y_{i}=1 \mid x_{i}, z_{i}, w_{i}\right)=\Phi\left(\frac{\beta_{0}+\beta_{1} x_{i}+\beta_{2} z_{i}}{\sigma_{i}}\right), \\
& \sigma_{i}=\exp \left(\gamma_{1} z_{i}+\gamma_{2} w_{i}\right),
\end{aligned}
$$

\footnotetext{
${ }^{16}$ Political advertisements on television are prohibited in Switzerland.

${ }^{17}$ The idea that heteroscedasticity is a substantially relevant phenomenon is not completely novel in political science (e.g., Downs and Rocke 1979). However, political scientists have only recently begun to explicitly model heterogeneous processes. For an overview, see Braumoeller (2006). Some very interesting examples include Alvarez and Brehm, who study the effect of ambivalence towards abortion (1995) and racial policies (1997), and Gerber and Lupia's (1993) study of campaign effects on the responsiveness of outcomes in direct legislation elections.
} 
where (3) describes the systematic component of the probit model, and (4) specifies a model for the heteroscedastic parameter which also contains campaign intensity $w$ as a control variable. ${ }^{18}$ If, again, the conjecture that lengthy ballots induce variability into the choice function is correct, we would expect a positively signed $\gamma_{1}$ estimate.

After having set up a probit model that principally allows for the estimation of both directional and variance-altering types of effects, provisions for varying effects of the left-right preference score over propositions are still to be incorporated into the model. To do so, the above specification is re-conceptualized as a two-level model with vote choices at level one nested in propositions $j$. This allows us to specify a random proposition-specific slope for the left-right score $x$. To take further advantage of the multilevel structure, we may also introduce a proposition-specific intercept in order to capture unobserved heterogeneity at the level of propositions. Unobserved heterogeneity at this level will occur if propositions differ in their proneness to get rejected, regardless of how voters' policy preferences are distributed in the electorate, which probably holds, for example, for popular initiatives versus mandatory referendums ${ }^{19}$ in Switzerland (see Kriesi 2005). The model now takes the form:

$$
\operatorname{Pr}\left(y_{i j}=1 \mid x_{i j}, z_{j}, w_{j}, \zeta_{1 j}, \zeta_{2 j}\right)=\Phi\left(\frac{\left(\beta_{0}+\zeta_{1 j}\right)+\left(\beta_{1}+\zeta_{2 j}\right) x_{i j}}{\exp \left(\gamma_{1} z_{j}+\gamma_{2} w_{j}\right)}\right) .
$$

Here $\zeta_{1 j}$ represents the deviation of proposition $j$ 's intercept from the mean intercept $\beta_{0}$, and $\zeta_{2 j}$ is the deviation of $j$ 's slope from the mean left-right score slope $\beta_{1}$. The parameters $\zeta_{1}$ and $\zeta_{2}$ are assumed to have a bivariate normal distribution with zero mean and covariance matrix elements $\vartheta_{11}, \vartheta_{12}, \vartheta_{21}$ and $\vartheta_{22}$, where $\vartheta_{21}=\vartheta_{12}$. Once conditioned on $\zeta_{j 1}, \zeta_{j 2}$ and the covariates, the vote choices $y$ are assumed to be independent. ${ }^{20}$ If there was random variation of the left-right preference score over propositions, we would expect a significant variance estimate $\vartheta_{22}$ of the random slope $\zeta_{2 j}$. Equally, we would expect significant variance $\vartheta_{11}$

\footnotetext{
${ }^{18}$ The exponential functional form is usually chosen for technical reasons since it guarantees that the variance is positive. However, Bowler et al.'s (1992) claim that information demands will increase exponentially with increasing ballot length, and Kriesi's (2005) and Nicholson's (2003) diverging findings on the effects of ballot length on the voters' awareness of propositions (see footnote 7) additionally lend substantial justification to this specification.

${ }^{19}$ Mandatory referendums are referendums that must be held in the event that the Federal Assembly, i.e., both chambers of the national parliament, decides to carry out a total or partial revision of the Federal Constitution, to join an organisation for collective security (e.g., the UN) or a supranational community (e.g., the EU) or to introduce urgent federal legislation without the required constitutional basis. For a definition of popular referendums, see footnote 13 .

${ }^{20}$ To be sure, the two-level structure that is set up here is an oversimplification. Recall that each VOX poll surveys a sample of individuals on their votes and preferences on all the propositions on a respective ballot. Therefore, individual choices are hierarchically nested in voters, and voters are clustered in ballots. But while the voters' choices are also nested in propositions, and propositions are nested in ballots, there is no strict hierarchy between voters and propositions, i.e., voters and propositions are crossed factors (see, for example Rasbash and Goldstein 1994). Unobserved heterogeneity would equally emanate from ballots and voters, for example, if our status quo bias hypothesis applied and we failed to model the effect of ballot length, or if some obstructionist or uninformed individuals had constantly lower propensities to cast a 'Yes' vote, irrespective of their policy preferences and the proposition at stake. To account for these eventualities is very burdensome computationally, since the number of random effects in cross-classified structures is way higher than in strictly hierarchical models. In fact, I have fitted an 'empty' cross-classified model (i.e., a model with random intercepts but without covariates) to the data using gllamm (see footnote 21), which took more than 200 hours to converge on a standard desktop computer. The results indicated by far the highest random intercept variation for propositions, and relatively low random variation for voters and ballots. Therefore, I have excluded these effects in the present model for the sake of computational tractability.
} 
of the random intercept $\zeta_{j 1}$ if there was unobserved heterogeneity of the kind exemplified above. Statistical results are presented in the following section. ${ }^{21}$

\section{Findings}

Table 1 reports the estimates of the random-effects heteroscedastic model of vote choice fit to voter survey and contextual data from 85 ballot propositions in Switzerland. First of all, and contrary to the pessimistic claims that ordinary voters are not competent to make meaningful choices in direct legislation elections, voters' preferences as measured by their left-right self-placements turn out to have a highly significant effect on their vote choices in the single-proposition case. This result is in line with previous findings by Bowler and Donovan (1998) and Magleby (1984), amongst others. However, propositions vary in the magnitudes of the effects of left-right scores on voting behavior, which is indicated by the significant estimate of the random slope variance, $\vartheta_{22}$. In other words, even though this analysis focuses on propositions that polarized the Swiss political elites along the left-right ideological continuum, there still seem to be differences between the propositions as to their potential to polarize self-identified left and right voters. This is a highly plausible finding, since the selection criteria for propositions, i.e., ideologically consistent party endorsements,

Table 1 Estimates from the random-effects heteroskedastic probit model of vote choice

\begin{tabular}{llc}
\hline & Estimate & S.E. \\
\hline Fixed part: choice function & & 0.016 \\
Left-right score $\left(\beta_{1}\right)$ & $0.241^{\mathrm{a}}$ & 0.026 \\
Ballot length $\left(\beta_{2}\right)$ & -0.040 & 0.086 \\
Constant $\left(\beta_{0}\right)$ & -0.050 & 0.018 \\
Fixed part: variance function & & 0.020 \\
Ballot length $\left(\gamma_{1}\right)$ & $0.047^{\mathrm{a}}$ & 0.054 \\
Campaign intensity $\left(\gamma_{2}\right)$ & 0.009 & 0.006 \\
Random part & & 0.006 \\
Intercept variance $\left(\vartheta_{11}\right)$ & $0.318^{\mathrm{a}}$ & $70.1 \%$ \\
Left-right score slope variance $\left(\vartheta_{22}\right)$ & $0.030^{\mathrm{a}}$ & $-23,673$ \\
Intercept-slope covariance $\left(\vartheta_{21}\right)$ & $-0.021^{\mathrm{a}}$ & 40,040 \\
Correctly predicted & & 85 \\
Log likelihood & & \\
N (Observations) & & \\
N (Propositions) & & \\
\hline
\end{tabular}

${ }^{\text {a Significant at } p<0.01}$

21 I have fitted this model to the referendum data with gllamm, a Stata program for generalized linear latent and mixed models (Rabe-Hesketh and Skrondal 2005). I have used adaptive quadrature to integrate out the random effects and the Newton-Raphson method to maximize the model's marginal likelihood. These procedures are reported to be efficient in random-effects binary dependent variable models with large level-1 clusters (Skrondal and Rabe-Hesketh 2004). 
do not contain any information as pertains to the intensity of left-right polarization. Therefore, the decision to include a random slope term for the left-right score into the model turns out to be justified. The same applies to the random proposition intercepts. They also vary significantly, as the estimate of $\vartheta_{11}$ indicates. That means propositions differ in their proneness to being passed or rejected, other things being equal. Kriesi (2005) has already demonstrated such differences with regard to certain types of direct legislation elections. He has argued that popular initiatives almost always fail since, first, trust in the national government is widespread among Swiss voters, second, the government issues pro endorsements in the case of obligatory referendums and con endorsements in the case of initiatives most of the time, and third, many voters most of the time follow the national government's recommendations, irrespective of their own ideological stances. Finally, the covariance term $\vartheta_{21}$ signifies that the random intercepts and slopes are negatively related. That means that higher proposition-specific intercepts tend to go hand in hand with left-right score effects of lower magnitudes, which might be simply interpreted as a ceiling effect.

Turning now to the estimates of greatest substantial interest for this study, we indeed find a negative directional effect of ballot length on the voters' propensity to cast a 'Yes' vote, which corresponds to the expectation of an increasing status quo bias under rising uncertainty. However, the coefficient is slightly below conventional levels of significance $(p=0.12)$. Therefore, this relatively weak finding casts some doubts on Bowler and Donovan's (1998) previous results indicating a significant decrease in the share of 'Yes' votes per additional proposition in official election data from California and Oregon. ${ }^{22}$

Of course, this does not mean that the number of propositions did not seriously affect voting behavior at all. On contrary, there is a highly significant variance-altering effect of ballot length. The positive estimate of $\gamma_{1}$ indicates that increasing numbers of propositions have raised the variability of the vote function that translates voters' preferences into choices. To further illustrate what this means, I have plugged the estimate of $\gamma_{1}$ into (4) to generate predicted variances over the observed range of numbers of propositions, i.e., from 1 to 9 . Campaign intensity, the control variable which does not exert a significant effect on the heterogeneity of the vote function, ${ }^{23}$ is kept constant at its mean (0). As we can see from Fig. 3 , the variance of the vote function approximately doubles when voters had to vote on 8 or 9 propositions on a ballot as compared to single-propositions ballots. ${ }^{24}$ But what does this precisely add up to in regard to the voters' ability to turn their preferences into consistent choices? As becomes clear from (5), the heteroscedastic component, i.e., the denominator of the model, 'scales' the systematic component in the numerator, which implies that the coefficients of the systematic component will decrease the larger the denominator of the equation gets. This effect is illustrated in Fig. 4, which this time plots predicted probabilities of a 'Yes' vote over the full range of the left-right score. The random deviations $\zeta_{j 1}$ and $\zeta_{j 2}$ from the mean intercept and the mean slope of the left-right score, as well as the control variable campaign intensity are kept constant at zero. Ballot length is varied from one (the

\footnotetext{
${ }^{22}$ The aggregate correlation between 'No' votes and ballot length in our data is just 0.02 as well.

${ }^{23} \mathrm{An}$ ad hoc interpretation of this unexpected finding would be that campaigns may not only serve to reduce the voters' uncertainty, but may also exert directional effects, i.e., persuade voters to approve or reject a proposition, irrespective of their underlying left-right orientations.

${ }^{24}$ An alternative reading of this finding would be that longer ballots imply enhanced levels of turnout, since any given proposition will have its own share of attentive voters. These 'issue publics', in turn, might not be in the position to make informed choices on all the propositions at stake (I am grateful to an anonymous reviewer for calling my attention to this). However, I did not find any relationship between ballot length and turnout in an aggregate analysis of the Swiss popular votes 1960-2004 (their correlation is just 0.05).
} 
Fig. 3 Predicted variance of the choice function by numbers of propositions

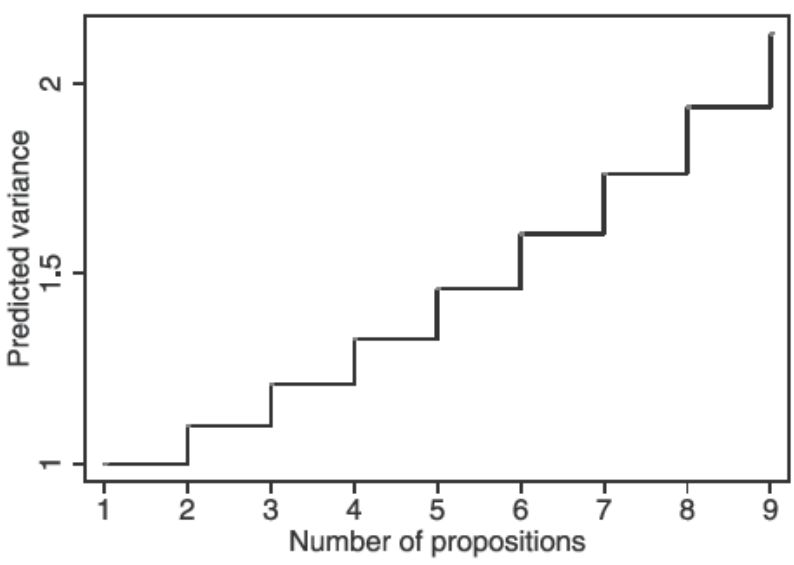

Fig. 4 Predicted probabilities of a 'Yes' vote over individual left-right scores. The number of propositions is varied from 1 (steepest/darkest curve) to 9 (flattest/lightest curve). Level-2 residuals and campaign intensity are held constant at their means

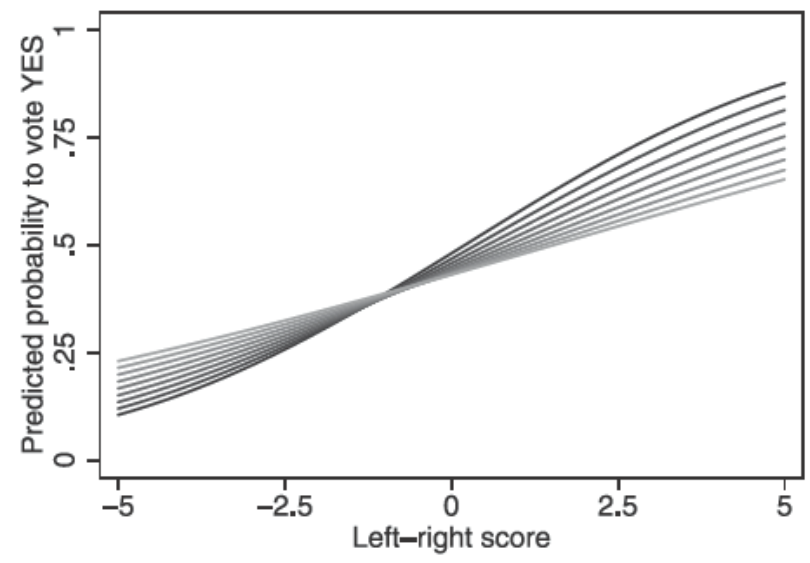

steepest, black curve) to nine legislative measures (the flattest, lighter curve). This figure shows how increasing variability due to growing numbers of propositions affects voters' choices: it attenuates the vote function that links preferences to choices. While the average difference in the probability of casting a 'Yes' vote between voters at the extremes of the left-right scale is approximately 0.78 in single-proposition elections, this difference shrinks to around 0.58 in elections on 5 propositions, and to 0.42 in a referendum that includes the observed maximum of 9 ballot measures. Thus, vote choices become ideologically more and more inconsistent, the longer the ballot gets.

What are the political consequences of these findings? Put differently, what if all the propositions under study had been submitted to a popular vote separately? Would it have made any difference regarding election outcomes? In an attempt to answer this hypothetical question, I have set up a simple counterfactual in Fig. 5. In a first step, I have used the model estimates, predicted values of propositions-specific intercept and slope deviations, ${ }^{25}$ and observed values of the covariates to calculate average probabilities to cast a 'Yes' vote per proposition, i.e., predicted shares of 'Yes' votes under actual conditions. In a second

${ }^{25}$ I have used gllapred, a postestimation module for gllamm, to obtain empirical Bayes predictions of $\zeta_{j 1}$ and $\zeta_{j 2}$ (see Rabe-Hesketh and Skrondal 2005). 
Fig. 5 Aggregate effects of ballot length on outcomes of direct legislation elections: predicted shares of 'Yes' votes for 85 propositions under actual (horizontal axis) and counterfactual conditions (vertical axis)

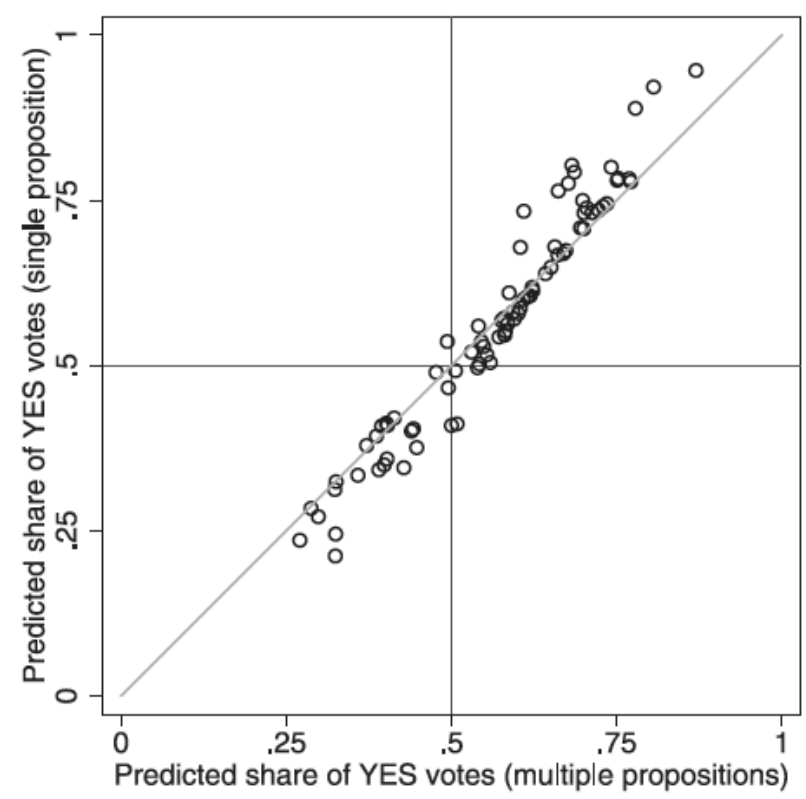

step, I have repeated this procedure while keeping ballot length constant at one proposition. The difference between these predictions, i.e., the deviations of points from the diagonal of Fig. 5, give us an impression of what probably would have happened if all the ballot measures under study were voted on alone. The average deviation between predicted shares of 'Yes' votes under actual and counterfactual conditions turns out to be 3 percentage points, with a considerable maximum of 12 percentage points. However, according to our predictions, only a handful of close referendums and initiatives are under serious suspicion of having yielded substantially different outcomes in terms of passage or rejection, represented by the points in or close to the upper-left and lower-right quadrants of the graph.

\section{Discussion}

In the introduction to this paper, I quoted Dubois and Feeney (1998), who observed that relatively little is known concerning how many issues voters in direct legislation elections can absorb at a given time. Although this study cannot answer this question in terms of a precise threshold number of propositions that voters can handle at once, it has given clear indication that ballot length gradually interferes with the voters' capabilities of translating their preferences as measured by ideological self-placements into policy choices. From a theoretical standpoint, this study therefore corroborates Braumoeller (2006) recent claim that political scientists should broaden their understanding of causation to include variance-altering types of causal effects. I have sketched a random-effects heteroscedastic probit modeling framework that is easily applied to a wide range of substantial questions, since it carries the potential to incorporate multilevel data structures that are so typical of our discipline. In a political perspective, the trend toward lengthy ballots that can be observed in countries and states with strong direct democratic traditions should raise serious concerns among government officials and legislators, since voters, like all decision-makers, are limited in their information-processing capacities. 
To be sure, these findings are based on a collection of Swiss direct legislation elections and are thus not readily extrapolated to other settings. We can only imagine what happens, for example, in statewide ballot elections in the United States, where ballots that include over 20 propositions, along with another multiplicity of candidates for various offices, are not uncommon, and where endorsements by the government and the political parties are typically less visible than in Switzerland. However, reducing the number of propositions per ballot is not an easy venture. For example, increasing the number of signatures required to qualify a measure for the ballot may potentially boost the influence of financially strong specialinterest groups (see, for example Gerber 1999). Increasing the frequency of referendums in order to reduce the number of propositions per ballot, on the other hand, may enhance the development of voter fatigue, i.e., lower turnout rates, and will surely raise the costs of elections. Finally and most radically, limiting the scope of direct in favor of representative democracy in order to reduce the number of propositions per ballot is no obvious solution either, since there is no guarantee that legislatures' decisions will better reflect the voters' preferences than direct legislation elections even under the present conditions do (Cronin 1989; Lupia and Matsusaka 2004).

Acknowledgements A previous version of this paper has been presented at the brown bag seminar of the Center for Comparative and International Studies, University and ETH Zurich. The author is grateful to the participants - plus or in particular Simon Hug, Hanspeter Kriesi, Martin Kroh, Romain Lachat, and Tobias Schulz - as well as the anonymous reviewers and editors for their valuable comments.

\section{References}

Alvarez, R. M. (1999). Information and elections. Ann Arbor: Michigan University Press.

Alvarez, R. M., \& Brehm, J. (1995). American ambivalence towards abortion policy: development of a heteroskedastic probit model of competing values. American Journal of Political Science, 39, 1055-1082.

Alvarez, R. M., \& Brehm, J. (1997). Are Americans ambivalent towards racial policies? American Journal of Political Science, 41, 345-374.

Alvarez, R. M., \& Brehm, J. (2002). Hard choices, easy answers. Princeton: Princeton University Press.

Alvarez, R. M., \& Franklin, C. H. (1994). Uncertainty and political perceptions. Journal of Politics, 56, 671-688.

Banducci, S. A. (1998). Searching for ideological consistency in direct legislation voting. In S. Bowler, T. Donovan \& C. J. Tolbert (Eds.), Citizens as legislators. Direct democracy in the United States. Columbus: Ohio State University Press.

Bartels, L. M. (1986). Issue voting under uncertainty: an empirical test. American Journal of Political Science, 30, 709-728.

Benz, M., \& Stutzer, A. (2004). Are voters better informed when they have a larger say in politics? Evidence for the European Union and Switzerland. Public Choice, 119, 31-59.

Bowler, S., \& Donovan, T. (1994). Information and opinion change on ballot propositions. Political Behavior, $16,411-435$.

Bowler, S., \& Donovan, T. (1998). Demanding choices: opinion, voting, and direct democracy. Ann Arbor: University of Michigan Press.

Bowler, S., Donovan, T., \& Happ, T. (1992). Ballot propositions and information costs: direct democracy and the fatigued voter. Western Political Quarterly, 45, 559-568.

Branton, R. P. (2003). Examining individual-level voting behavior on state ballot propositions. Political Research Quarterly, 56, 367-377.

Braumoeller, B. F. (2006). Explaining variance; or, stuck in a moment we can't get out of. Political Analysis, $14,268-290$.

Brockington, D. (2003). A low information theory of ballot position effect. Political Behavior, 25, 1-27.

Christin, T., Hug, S., \& Sciarini, P. (2002). Interest and information in referendum voting: an analysis of swiss voters. European Journal of Political Research, 41, 759-776.

Cronin, T. E. (1989). Direct democracy. Cambridge: Harvard University Press.

Darcy, R., \& McAllister, I. (1990). Ballot position effects. Electoral Studies, 9, 5-17. 
Downs, G. W., \& Rocke, D. M. (1979). Interpreting heteroscedasticity. American Journal of Political Science, 23, 816-828.

Dubois, P. L., \& Feeney, F. (1998). Lawmaking by initiative: issues, opinions, and comparisons. New York: Agathon Press.

Enelow, J. M., \& Hinich, M. J. (1984). The spatial theory of voting. An introduction. Cambridge: Cambridge University Press. J. M. Enelow, M. J. Hinich, Includes index. Bibliography: pp. 224-228.

Frey, B. S. (1994). Direct democracy: politico-economic lessons from swiss experience. The American Economic Review, 84, 338-342.

Gerber, E. R. (1999). The populist paradox: interest group influence and the promise of direct legislation. Princeton: Princeton University Press.

Gerber, E. R., \& Lupia, A. (1993). When do campaigns matter? Informed votes, the heteroscedastic logit and the responsiveness of electoral outcomes. Social science working paper 814. Pasadena: California Institute of Technology.

Gerber, E. R., \& Lupia, A. (1995). Campaign competition and policy responsiveness in direct legislation elections. Political Behavior, 17, 287-306.

Harvey, A. C. (1976). Estimating regression models with multiplicative heteroscedasticity. Econometrica, 44, 461-465.

Hug, S., \& Schulz, T. (2007). Left-right positions of political parties in Switzerland. Party Politics, 13, 305330 .

Kahneman, D., Knetsch, J. L., \& Thaler, R. H. (1991). Anomalies: the endowment effect, loss aversion, and status quo bias. The Journal of Economic Perspectives, 5, 193-206.

Kriesi, H. (2005). Direct democratic choice. The swiss experience. Oxford: Lexington.

Krosnick, J. A., \& Miller, J. A. (1998). The impact of candidate name order on election outcomes. Public Opinion Quarterly, 61, 291-330.

Lapalombara, J. G., \& Hagan, C. B. (1951). Direct legislation: an appraisal and a suggestion. American Political Science Review, 45, 400-421.

LeDuc, L. (2002). Referendums and initiatives: the politics of direct democracy. In L. LeDuc, R. G. Niemi \& P. Norris (Eds.), Comparing democracies 2. New challenges in the study of elections and voting. London: Sage.

Lijphart, A. (1997). Unequal participation: democracy's unresolved dilemma. American Political Science Review, 91, 1-14.

Lupia, A. (1992). Busy voters, agenda control, and the power of information. American Political Science Review, 86, 390-403.

Lupia, A. (1994). Shortcuts versus encyclopedias: information and voting behavior in California insurance reform elections. American Political Science Review, 88, 63-76.

Lupia, A., \& Matsusaka, J. G. (2004). Direct democracy: new approaches to old questions. Annual Review of Political Science, 7, 463-482.

Lupia, A., \& McCubbins, M. D. (1998). The democratic dilemma. Cambridge: Cambridge University Press.

Magleby, D. (1984). Direct legislation: voting on ballot propositions in the United States. Baltimore: Johns Hopkins University Press.

Matsusaka, J. G. (1995). Explaining voter turnout patterns: an information theory. Public Choice, 84, 91-117.

Matsusaka, J. G. (2005). Direct democracy works. Journal of Economic Perspectives, 19, 185-206.

Mueller, J. E. (1969). Voting on the propositions: ballot patterns and historical trends in California. American Political Science Review, 63, 1197-1212.

Nicholson, S. P. (2003). The political environment and ballot proposal awareness. American Journal of Political Science, 47, 403-410.

Quattrone, G. A., \& Tversky, A. (1988). Contrasting rational and psychological analyses of political choice. American Political Science Review, 82, 719-736.

Rabe-Hesketh, S., \& Skrondal, A. (2005). Multilevel and longitudinal modeling using stata. College Station: Stata Press.

Rasbash, J., \& Goldstein, H. (1994). Efficient analysis of mixed hierarchical and cross-classified random structures using a multilevel model. Journal of Educational and Behavioral Statistics, 19, 337-350.

Samuelson, W., \& Zeckhauser, R. (1988). Status quo bias in decision making. Journal of Risk and Uncertainty, 1, 7-59.

Shepsle, K. A. (1972). The strategy of ambiguity. American Political Science Review, 66, 555-568.

Skrondal, A., \& Rabe-Hesketh, S. (2004). Generalized latent variable modeling: multilevel, longitudinal and structural equation models. Boca Raton: Chapman \& Hall. 
Sniderman, P. M., Brody, R. A., \& Tetlock, P. E. (1993). Reasoning and choice. Explorations in political psychology. Cambridge: Cambridge University Press.

Tolbert, C. J., McNeal, R., \& Smith, D. A. (2003). Enhancing civic engagement: the effect of direct democracy on political participation and knowledge. State Politics and Policy Quarterly, 3, 23-41.

Yatchew, A., \& Griliches, Z. (1985). Specification error in probit models. Review of Economics and Statistics, $18,134-139$.

Zaller, J. (1992). The nature and origins of mass opinion. Cambridge: Cambridge University Press. 